\title{
Modified Predator-Prey Model for Mealybug Population with Biological Control
}

\author{
Jairaj Promrak ${ }^{1,2, *}$, Graeme Wake ${ }^{2}$, Chontita Rattanakul ${ }^{1,3}$ \\ 1. Department of Mathematics, Faculty of Science, Mahidol University, Thailand. \\ 2. Institute of Natural and Mathematical Sciences, Massey University, Auckland, New Zealand. \\ 3. Centre of Excellence in Mathematics, Commission on Higher Education, Thailand.
}

Received: February 23, 2016 / Accepted: March 21, 2016 / Published: May 25, 2016.

\begin{abstract}
Mealybugs are a major pest for many crops (such as the vegetable Cassava, in Thailand). An environmentally-friendly bio-control method is implemented using an introduced predator (green lacewings) of the mealybugs to mitigate plant damage. This is analyzed so as to devise and determine an optimal strategy for control of the mealybug population. A predator-prey model has been proposed and analyzed to study the effect of the biological control of the spread of the mealybugs in the plant field. The behaviour of the system in terms of stability, phase space and bifurcation diagrams are considered. The results obtained from different numbers of predators being released are compared. In particular we obtain thresholds of introduced-predator level above which the prey is driven to extinction. Future models will include age-structured multi-compartments for both the prey and predator populations.
\end{abstract}

Keywords: Predator-prey model, mealybug, biological control

\section{Introduction}

Mealybugs are a type of scale insect which is belongs to the family Pseudococcidae, order Homoptera (Johnson and Triplehorn, 2004). They are serious pests that infest a wide range of agricultural, horticultural and forest species including cassava, mango, tomato, peach, grape vine, redcurrant, cotton and orchid (Royal Horticultural Society, 2015). In 1980 s, exotic mealybugs caused $50-90 \%$ loss of mango yields in West Africa (Moore, 2004). In 1999, the cost of Postharvest Management (PHM) of the pink hibiscus mealybug invading crops in the U.S. was estimated to be around $\$ 750$ million per year in the absence of control (Moffitt, 1999). During 2006-2007, the economic damage caused by mealybug in cotton area reached $\$ 500,000$ in north India while 0.2 million bales and 50,000 acres of cotton region were destroyed in Pakistan (Nagrare et

Corresponding author: Jairaj Promrak, Department of Mathematics, Faculty of Science, Mahidol University, Thailand. E-mail:.jpjairaj@gmail.com. al., 2009; Institute of Science in Society, 2010). In 2008 , the spread of cassava mealybug over 160,000 hectares led to a 8-10 million tonnes decrease in the cassava production in Thailand (Department of agriculture, 2008). Not only is this an enormous economic loss, but these pest infestations also cause social and cultural problems.

To control mealybug population, the biological method by releasing natural enemies has proved experimentally to be successful as shown in Table 1 . Although the impact of the biological control of mealybugs has been widely tested, there are few established theoretical models to support such projects.

Mathematical modelling is an important tool to study the behaviour of prey and its predator populations. It allows us to determine the range of parameters required for a stable system and also provides a way of determining the effect when conditions are changed, especially where there is a distinct abrupt change in the long-term behaviour. Determination of these 
Table 1 Successful experiments in controlling mealybugs using its natural enemies.

\begin{tabular}{|c|c|c|c|c|}
\hline Mealybug & Natural enemy & Plant & Area & Reference \\
\hline Phenacoccus manihoti & $\begin{array}{l}\text { Parasitoid: } \\
\text { Epidinocarsis lopezi }\end{array}$ & Cassava & Africa & Herren et al., 1991 \\
\hline $\begin{array}{l}\text { Rastrococcus invadens } \\
\text { Williams }\end{array}$ & $\begin{array}{l}\text { Parasitoid: } \\
\text { Gyranusoidea tebygi } \\
\text { Noyes }\end{array}$ & Mango & Benin & $\begin{array}{l}\text { Bokonon-ganta et } \\
\text { al.,1995 }\end{array}$ \\
\hline \multirow{4}{*}{ Maconellicoccus hirsutus } & Encyrtid wasps & - & - & Kairo et al., 2000 \\
\hline & Coccinellid beetles & Sapota (India) & India, Caribbean, Egypt & $\begin{array}{l}\text { Mani et al., } 2008 \\
\text { Baskaran et al., } 2007 \\
\text { Kairo et al., } 2000 \\
\end{array}$ \\
\hline & $\begin{array}{l}\text { Parasitoid: } \\
\text { Anagyrus kamali and } \\
\text { Achrysopophagussp. }\end{array}$ & - & Egypt & Bartlett, 1978 \\
\hline & $\begin{array}{l}\text { Metarhizium anisopliae } \\
\text { var. acridum }\end{array}$ & - & Laboratory & Ujjan et al., 2007 \\
\hline
\end{tabular}

thresholds is crucial for effective management of the situations.

The aim of this paper is to apply methods from the theory of dynamical systems to pest-control problem. We modify the predator-prey equations to analyze mealybug population with and without releasing its natural enemy. In the beginning, the population dynamics of two species using the predator-prey equations have been studied.

Let $P$ and $M$ be the population size of prey (mealybugs) and predator respectively. The first mathematical model is given by the following system of coupled differential equations:

$$
\begin{gathered}
\frac{d P}{d t}=a P\left(1-\frac{P}{K}\right)-b P M=f_{1} \\
\frac{d M}{d t}=-c M+d P M=f_{2}
\end{gathered}
$$

$a P(1-P / K)$ and $c M$ are the growth rate of prey and death rate of predator, respectively. Further, $b P M$ represents the decreasing rate of prey caused by its predator whereas $d P M$ is the increasing rate of predator growth depending on its prey. This model is corresponding to the following assumptions:

(i) Prey grows logistically.

(ii) Predator eats only the particular prey, under a mass-action law.

By solving equations (1) and (2), we can obtain the behaviour of the system in terms of steady states, phase planes and bifurcation diagrams which are the main focus of this work.

The outline of this paper is as follows. In section 2, the models and theoretical solutions are given. Numerical simulations and bifurcation diagrams are presented in section 3. Section 4 is devoted to discussion our results. Finally, in section 5, we draw conclusions and suggest the idea for future research.

\section{Methods}

In this work, three models are considered. The first model is the original predator-prey model with logistic growth for prey. The last two models are modified predator-prey models by adding the natural enemy continuously and periodically.

\subsection{Predator-prey Model}

Assume that $a, b, c, d$, and $K$ are positive parameters. A predator-prey model is shown in equations (1) and (2). To deal with a system of two first-order equations, the eigenvalue-eigenvector method is applied.

\subsubsection{Steady-state solutions}

A steady state (also called equilibrium point or fixed point) is a situation in which the system does not change [10]. Setting derivatives equal to zero; $d P / d t=0$ and $d M / d t=0$. Equations (1) and (2) become

$$
a P\left(1-\frac{P}{K}\right)-b P M=0
$$




$$
-c M+d P M=0 .
$$

From equations (3) and (4), we obtain three steady states which are $\left(P_{s 1}, M_{s 1}\right)=(0,0),\left(P_{s 2}, M_{s 2}\right)=$ $(K, 0)$ and $\left(P_{s 3}, M_{s 3}\right)=(c / d, a / b(1-c / d K))$.

Get better setting out. Call them respectively "Extinction", "Monospecies" and "Coexisting species". The last one is feasible if and only if $c<d K$.

\subsubsection{Stability}

After finding all steady-states, the type of each point is specified to complete the solution's diagram. From (1) and (2), the Jacobian matrix of this system is

$$
\begin{aligned}
& J_{\left(P_{s}, M_{s}\right)}=\left[\begin{array}{ll}
\frac{\partial f_{1}}{\partial P} & \frac{\partial f_{1}}{\partial M} \\
\frac{\partial f_{2}}{\partial P} & \frac{\partial f_{2}}{\partial M}
\end{array}\right]_{\left(P_{s}, M_{s}\right)} \\
& =\left[\begin{array}{cc}
a-\frac{2 a P}{K}-b M & -b P \\
d M & -c+d P
\end{array}\right]_{\left(P_{s}, M_{s}\right)} .
\end{aligned}
$$

At $\left(P_{s 1}, M_{s 1}\right)=(0,0)$, "extinction"

$$
J_{(0,0)}=\left[\begin{array}{cc}
a & 0 \\
0 & -c
\end{array}\right] \rightarrow \lambda_{1}=a, \lambda_{2}=-c
$$

where $a>0$ and $c>0$.

Since there is one eigenvalue which is positive and one which is negative, $\left(P_{s 1}, M_{s 1}\right)=(0,0)$ is an unstable saddle.

$$
\begin{aligned}
& \text { At }\left(P_{s 2}, M_{s 2}\right)=(K, 0), \text { " monospecies" } \\
& J_{(K, 0)}=\left[\begin{array}{cc}
-a & -b K \\
0 & d K-c
\end{array}\right] \rightarrow \lambda_{1}=-a, \lambda_{2}=d K-c
\end{aligned}
$$

where $a, c, d, K>0$.

$\left(P_{s 2}, M_{s 2}\right)=(K, 0)$ is stable if both eigenvalues are negative, i.e., $d K-c<0$.

At

$$
\left(P_{s 3}, M_{s 3}\right)=(c / d, a / b(1-c / d K)),
$$

"coexisting species"

$$
\begin{gathered}
J_{\left(\frac{c}{d^{\prime}}, \frac{a}{b}\left(1-\frac{c}{d K}\right)\right)}=\left[\begin{array}{cc}
-\frac{a c}{d K} & -\frac{b c}{d} \\
\frac{a}{b}\left(d-\frac{c}{K}\right) & 0
\end{array}\right] \\
\rightarrow \lambda=\frac{1}{2}\left(-\frac{a c}{d K} \pm \sqrt{\left(\frac{a c}{d K}\right)^{2}-4 \mathrm{ac}\left(1-\frac{c}{d K}\right)}\right)
\end{gathered}
$$

Case 1: $d K<c$

$$
\begin{aligned}
& \lambda_{1}=\frac{1}{2}\left(-\frac{a c}{d K}+\sqrt{\left(\frac{a c}{d K}\right)^{2}-4 \mathrm{ac}\left(1-\frac{c}{d K}\right)}\right)>0, \\
& \lambda_{2}=\frac{1}{2}\left(-\frac{a c}{d K}-\sqrt{\left(\frac{a c}{d K}\right)^{2}-4 \mathrm{ac}\left(1-\frac{c}{d K}\right)}\right)<0
\end{aligned}
$$

Since there is one eigenvalue which is positive and one which is negative, in this case, $\left(P_{s 3}, M_{s 3}\right)$ is an unstable saddle.

Case 2: $d K>c$

$$
\lambda_{1}<0, \lambda_{2}<0
$$

Both eigenvalues have negative real parts so this point is stable (either a node or a spiral in the phase-plane).

To verify that the stability is defined within the appropriate area, we will show that $R=\{(P, M): 0<$ $\left.K \leq P \leq c / d, 0<M \leq M_{0}\right\}$ is positively invariant. Let $A$ and $B$ be the upper bounds of $P$ and $M$ respectively. Consider the boundary region of four components:

$\Omega_{1}$ - straight segment from $(A, 0)$ to $(A, B)$,

$\Omega_{2}$ - straight segment from $(A, B)$ to $(0, B)$,

$\Omega_{3}$ - straight segment from $(0, B)$ to $(0,0)$,

$\Omega_{4}$ - straight segment from $(0,0)$ to $(A, 0)$, see Figure 1.

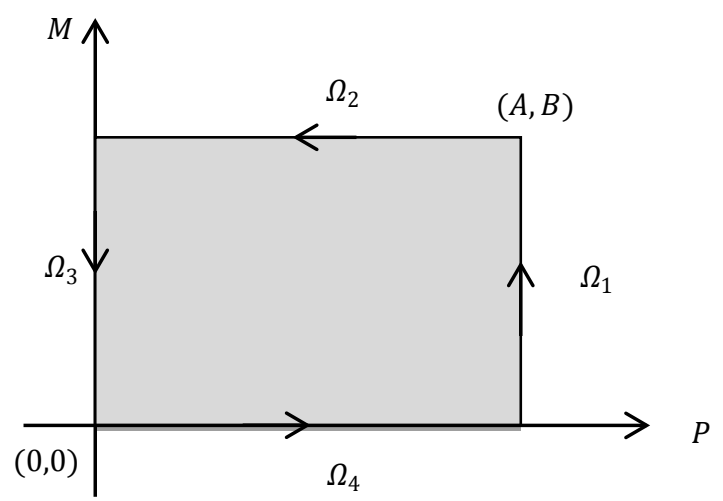

Fig. 1 A two-dimensional positively invariant region.

Choose the normal vectors $\overrightarrow{n_{1}}=(1,0)$ and $\overrightarrow{n_{2}}=$ $(0,1)$ to point outside the region for segments $\Omega_{1}$ and $\Omega_{2}$ whereas apply the normal vectors $\overrightarrow{n_{3}}=\overrightarrow{n_{1}}=$ $(1,0)$ and $\overrightarrow{n_{4}}=\overrightarrow{n_{2}}=(0,1)$ to point inside the area for 
segments $\Omega_{3}$ and $\Omega_{4}$ using dot product.

(a) Along $\Omega_{1},(\dot{P}, \dot{M}) \cdot(1,0) \leq 0$;

$$
\begin{aligned}
(\dot{P}, \dot{M}) \cdot(1,0)= & \dot{P}=a P\left(1-\frac{P}{K}\right)-b P M \\
& =a A\left(1-\frac{A}{K}\right)-b A M \leq 0 . \\
a A\left(1-\frac{A}{K}\right) \leq & b A M \rightarrow \frac{a}{b}\left(1-\frac{A}{K}\right) \leq M
\end{aligned}
$$

Since $0 \leq M \leq B, A \geq K$.

(b) Along $\Omega_{2},(\dot{P}, \dot{M}) \cdot(0,1) \leq 0$;

$$
\begin{gathered}
(\dot{P}, \dot{M}) \cdot(0,1)=\dot{M}=-c M+d P M \\
=-c B+d P B \leq 0 . \\
d P B \leq c B \rightarrow P \leq c / d .
\end{gathered}
$$

Since $0 \leq P \leq A, A \leq c / d$.

(c) Along $\Omega_{3}$,

$$
(\dot{P}, \dot{M}) \cdot(1,0)=\dot{P}=a P\left(1-\frac{P}{K}\right)-b P M=0 .
$$

That is, when $P=0, M$ is on the y-axis with $\dot{M}<0$ (cannot cross $\Omega_{3}$ ).

(d) Along $\Omega_{4}$,

$$
(\dot{P}, \dot{M}) \cdot(0,1)=\dot{M}=-c M+d P M=0 .
$$

That is, when $M=0, P$ is on the $\mathrm{x}$-axis with $\dot{P}>0$ (cannot cross $\Omega_{4}$ ).

(e) Find $B=\max \{M\}$.

$$
\begin{gathered}
\dot{M}=-c M+d P M \leq-c B+d P B \\
\leq-c B+d(c / d) B=0 \text { for } P \leq c / d . \\
\dot{M}<0 \rightarrow M(t)<M(0)=M_{0} .
\end{gathered}
$$

Let $t \geq 0$. Suppose $P(0) \in R$ and $M(0) \in R$. We then obtain $P(t) \in R$ and $M(t) \in R$, i.e., $R=$ $\left\{(P, M): 0<K \leq P \leq c / d, 0<M \leq M_{0}\right\} \quad$ is a positively invariant set with respect to equations (1) and (2) for $K \leq c / d$.

\subsection{New Model for Biological Control with Continuous effect}

Assume $P, M, a, b, c, d$, and $K$ are defined as in the previous model. We modify the predator-prey equations by adding a natural enemy of the mealybugs into the system at a positive constant rate $g$. Our new model is shown below.

$$
\frac{d P}{d t}=a P\left(1-\frac{P}{K}\right)-b P M=f_{1}
$$

$$
\frac{d M}{d t}=g-c M+d P M=f_{3}
$$

Then, we analyze this system in the same manner.

2.2.1 Steady-state solutions

Setting derivatives equal to zero; $d P / d t=0$ and $d M / d t=0$. Equations (5) and (6) become

$$
\begin{gathered}
a P\left(1-\frac{P}{K}\right)-b P M=0, \\
g-c M+d P M=0 .
\end{gathered}
$$

So, three steady states are $\left(P_{s s 1}, M_{s s 1}\right)=(0, g / c)$, $\left(P_{s s 2}, M_{s s 2}\right)=\left(P_{s s 2}, \frac{g}{c-d P_{s s 2}}\right) \quad$ and $\quad\left(P_{s s 3}, M_{s s 3}\right)=$ $\left(P_{s s 3}, \frac{g}{c-d P_{s s 3}}\right)$ where $P_{s s 2}$ and $P_{s s 3}$ are defined in equations (9) and (10), respectively.

$$
\begin{gathered}
P_{S S 2}=\frac{(a d K+c a)+\sqrt{(a d K+c a)^{2}-4 a d(c a K-g b K)}}{2 a d}, \\
P_{S S 3}=\frac{(a d K+c a)-\sqrt{(a d K+c a)^{2}-4 a d(c a K-g b K)}}{2 a d} .
\end{gathered}
$$

The first one only is a monospecies while the last two solutions are coexisting species.

\subsubsection{Stability}

The Jacobian matrix of (5) and (6) is

$$
\begin{aligned}
& J_{\left(P_{s s}, M_{s s}\right)}=\left[\begin{array}{ll}
\frac{\partial f_{1}}{\partial P} & \frac{\partial f_{1}}{\partial M} \\
\frac{\partial f_{3}}{\partial P} & \frac{\partial f_{3}}{\partial M}
\end{array}\right]_{\left(P_{s s}, M_{s s}\right)} \\
& =\left[\begin{array}{cc}
a-\frac{2 a P}{K}-b M & -b P \\
d M & -c+d P
\end{array}\right]_{\left(P_{s s}, M_{s s}\right)}
\end{aligned}
$$

$$
\text { At }\left(P_{s s 1}, M_{s s 1}\right)=(0, g / c) \text {, }
$$

$J_{(0, g / c)}=\left[\begin{array}{cc}a-\frac{b g}{c} & 0 \\ \frac{d g}{c} & -c\end{array}\right] \rightarrow \lambda_{1}=a-\frac{b g}{c}, \lambda_{2}=-c$ where $a, b, c, g>0$.

We obtain that $\left(P_{s s 1}, M_{s s 1}\right)=(0, g / c)$ is stable when $g>a c / b$ (both eigenvalues are negative).

$$
\text { At }\left(P_{s s 2}, M_{s s 2}\right)=\left(P_{s s 2}, \frac{g}{c-d P_{s s 2}}\right) \text {, }
$$




$$
\begin{gathered}
J_{\left(P_{s s 2}, \frac{g}{c-d P_{s s 2}}\right)} \\
=\left[\begin{array}{cc}
a-\frac{2 a P_{s s 2}}{K}-\frac{b g}{c-d P_{s s 2}} & -b P_{s s 2} \\
\frac{d g}{c-d P_{s s 2}} & -c+d P_{s s 2}
\end{array}\right] \\
\lambda^{2}-\left(a-\frac{2 a P_{s s 2}}{K}-\frac{b g}{c-d P_{s s 2}}-c+d P_{s s 2}\right) \lambda \\
-\left(a-\frac{2 a P_{s s 2}}{K}-\frac{b g}{c-d P_{s s 2}}\right)(c \\
\left.-d P_{s s 2}\right)+b P_{s s 2}\left(\frac{d g}{c-d P_{s s 2}}\right)=0
\end{gathered}
$$

The eigenvalue $\lambda$ can be calculated from the quadratic equation (12). However, for convenience, particular $\lambda$ for the corresponding parameters will be considered. In other words, the stability of equations (7) and (8) at $\left(P_{s s 2}, M_{s s 2}\right)$ and $\left(P_{s s 3}, M_{s s 3}\right)$ will be approached numerically by the following steps.

(i) Separate value of $g$.

(ii) Find the corresponding $P_{s s 2}$ and $P_{s s 3}$ from equations (9) and (10).

(iii) Apply equation (11) to obtain the Jacobian matrix.

(iv) Calculate the eigenvalues $\lambda$.

(v) Classify the stability.

By solving equations (7) and (8), we obtain

$$
\begin{gathered}
M=\frac{a}{b}\left(1-\frac{P}{K}\right), \\
M=\frac{g}{c-d P} .
\end{gathered}
$$

It leads to the following formula:

$$
g=\frac{a d P^{2}-(a d K+c a) P+c a K}{b K}
$$

Equation (15) is a parabola which has vertex at $\left(g^{*}, P^{*}\right)=\left(\frac{a c}{b}-\frac{(a d K+c a)^{2}}{4 a d b K}, \frac{K}{2}+\frac{c}{2 d}\right)$ and passes through the points

$$
(g, P)=(0, K),(0, c / d),(a c / b, 0) .
$$

Suppose

$$
K=1, a=1.3, b=0.5, c=0.7
$$

and

$$
d=1.6
$$

in appropriate units. The graph of $g$ is shown as Figure 2.

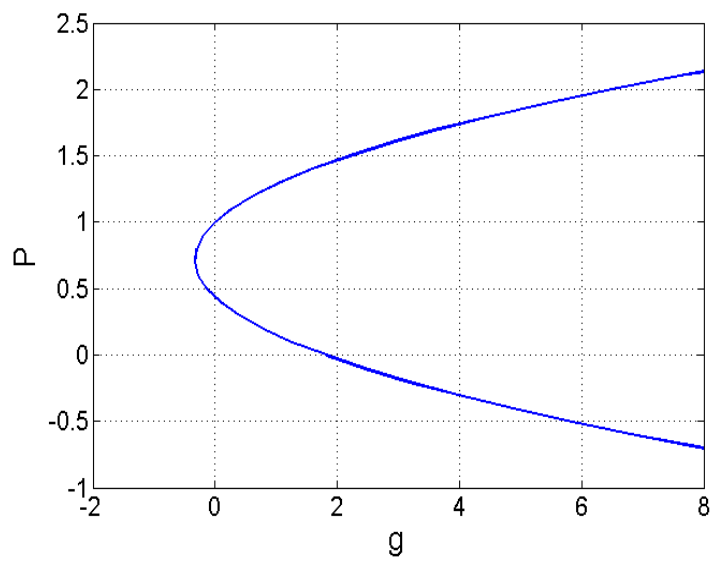

Fig. 2 Graph of $g$ against $P$.

Remark: (a) $P_{s s 2}$ is the upper half of the parabola and $P_{s s 3}$ is the lower half of it.

(b) $g^{*}=\frac{a c}{b}-\frac{(a d K+c a)^{2}}{4 a d b K}<0$.

Separate the graph into three regions based on the value of $g$ as follows:

$$
\begin{aligned}
& \text { R1. } g^{*}<g<0, \\
& \text { R2. } 0<g<a c / b, \\
& \text { R3. } g>a c / b .
\end{aligned}
$$

We pick up the value of $g$ for each region and then calculate the eigenvalue by the step as we mention earlier. Finally, the stability can be specified shown in Table 2.

Moreover, we found that the positively invariant region of equations (5) and (6) is $R=\{(P, M): 0<$ $K \leq P<c / d, M>0\}$ for $K \leq c / d$.

\subsection{New Model for Biological Control with Impulse Effect}

In practice, predator will be released not continuously but periodically so modified predator-prey equations with impulse effect are considered as follows: 
Table 2 Stability of modified predator-prey model at $\left(P_{s s 2}, M_{s s 2}\right)$ and $\left(P_{s s 3}, M_{s s 3}\right)$.

\begin{tabular}{|c|c|c|c|c|c|c|}
\hline Region & $g$ & $P_{S}$ & \multicolumn{2}{|c|}{ Jacobian matrix } & $\lambda$ & Stability \\
\hline$P_{s s 2}-\mathrm{R} 1$ & -0.2 & 0.89 & {$\left[\begin{array}{c}-1.16 \\
0.44\end{array}\right.$} & $\left.\begin{array}{c}-0.45 \\
0.73\end{array}\right]$ & $-1.05,0.62$ & unstable \\
\hline$P_{s s 2}-\mathrm{R} 2$ & 0.2 & 1.08 & {$\left[\begin{array}{l}-1.40 \\
-0.31\end{array}\right.$} & $\left.\begin{array}{c}-0.54 \\
1.02\end{array}\right]$ & $-1.47,1.09$ & unstable \\
\hline$P_{s s 2}-\mathrm{R} 3$ & 2.0 & 1.47 & {$\left[\begin{array}{l}-1.91 \\
-1.94\end{array}\right.$} & $\left.\begin{array}{c}-0.73 \\
1.65\end{array}\right]$ & $-2.27,2.01$ & unstable \\
\hline$P_{s s 3}-\mathrm{R} 1$ & -0.2 & 0.54 & {$\left[\begin{array}{c}-0.71 \\
1.90\end{array}\right.$} & $\left.\begin{array}{c}-0.27 \\
0.17\end{array}\right]$ & $-0.27 \pm 0.57 \mathrm{i}$ & stable \\
\hline$P_{s s 3}-\mathrm{R} 2$ & 0.2 & 0.36 & {$\left[\begin{array}{c}-0.47 \\
2.65\end{array}\right.$} & $\left.\begin{array}{l}-0.18 \\
-0.12\end{array}\right]$ & $-0.30 \pm 0.67 \mathrm{i}$ & stable \\
\hline$P_{s s 3}-\mathrm{R} 3$ & 2.0 & -0.03 & {$\left[\begin{array}{l}0.04 \\
4.28\end{array}\right.$} & $\left.\begin{array}{c}0.01 \\
-0.75\end{array}\right]$ & $0.11,-0.82$ & unstable \\
\hline
\end{tabular}

$$
\begin{gathered}
\frac{d P}{d t}=a P\left(1-\frac{P}{K}\right)-b P M \\
\frac{d M}{d t}=-c M+d P M, T_{i}<t<T_{i+1} \\
M\left(T_{i^{+}}\right)=M\left(T_{i^{-}}\right)+m, m=g *(\Delta t)
\end{gathered}
$$

where $P, M, a, b, c, d, g$ and $K$ are defined as section 2.2. Let $m$ be the size of the added predator with period $\Delta t$. The relationship of parameters in equations (17) and (18) can be drawn in Figure 3.

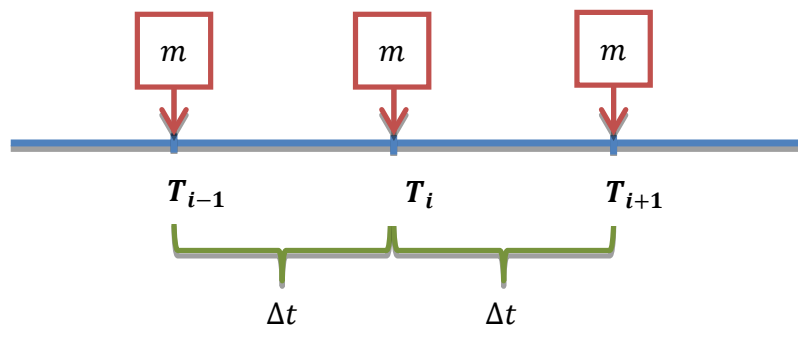

Fig. 3 Relationship of parameters for added predator.

The numerical results from this model will be shown and compared in section 3 .

\section{Simulation Results}

The simulation of models leads to the following numerical results. Firstly, we show illustrative phase plane plots for the original model where the arrows represent temporal changes. From Figure 4, we obtain that the solutions tend to the monospecies and the coexisting species steady states when $c=3.2$ and $c=0.7$ consecutively.

Secondly, the corresponding bifurcation diagrams of equations (1) and (2) are shown in Figure 5 where solid and dash lines represent stable and unstable states, respectively. We simplify the problem by assuming $b=d$. Then, long-term solutions depending on parameter $b$ can be explained. In the case that $d K<c$, solutions will converge to monospecies $\left(P_{s 2}, M_{s 2}\right)=(K, 0)$. Otherwise, they will tend to the coexisting species $\left(P_{s 3}, M_{s 3}\right)=$ $\left(\frac{c}{d}, \frac{a}{b}\left(1-\frac{c}{d K}\right)\right)$ where $P_{s 3}$ is strictly decreasing.

Next, we move to the bio-control model satisfying equations (5) and (6). Phase plane graphs with different rate of added predator are compared and shown in Figure 6. For $g=1$, solutions meet coexisting species steady state. And we obtain monospecies as a long-term solution when $g=3$.

Again, bifurcation diagrams are employed to determine the stability of the system. Since we focus on the effect of added predator to mealybug population, our bifurcation diagrams are drawn with respect to $g$. Recall from Figure 1 that $g$ can be negative (take some existing predators out of the system); however, it is out of our domain. From Figure (7a), we can see 


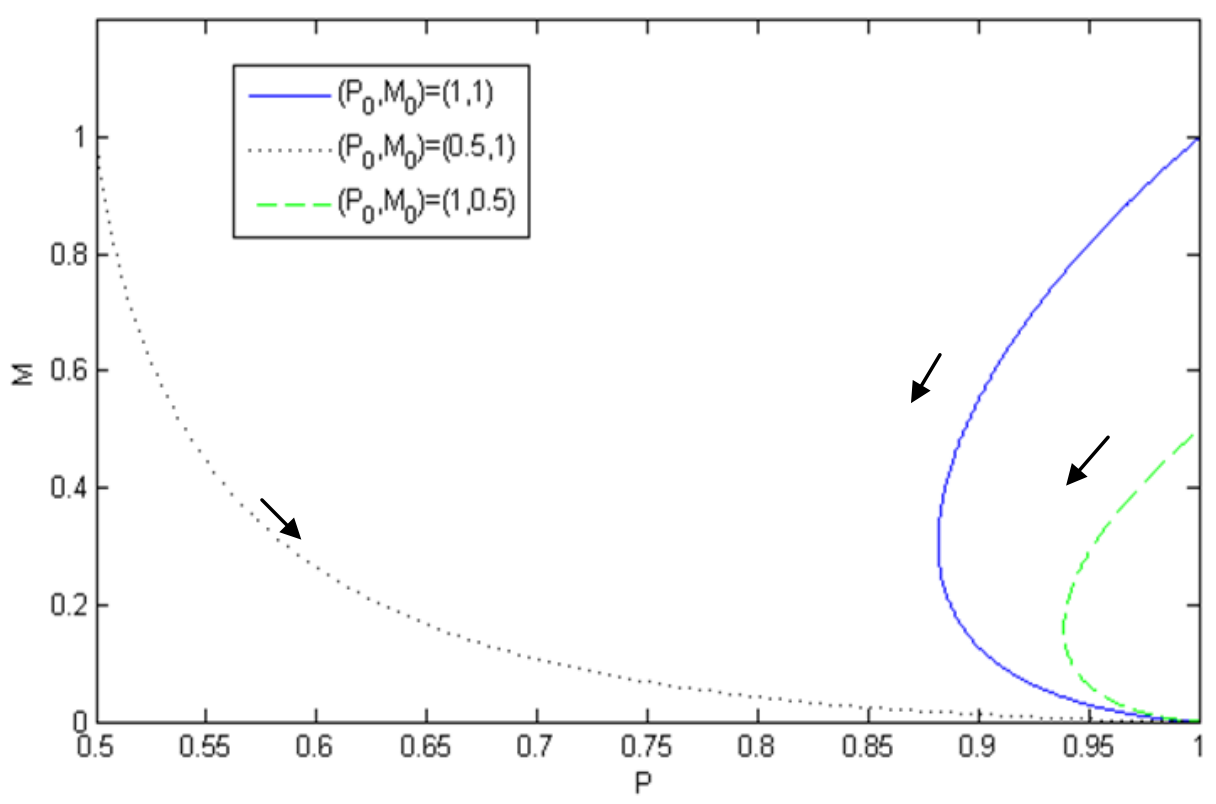

(a)

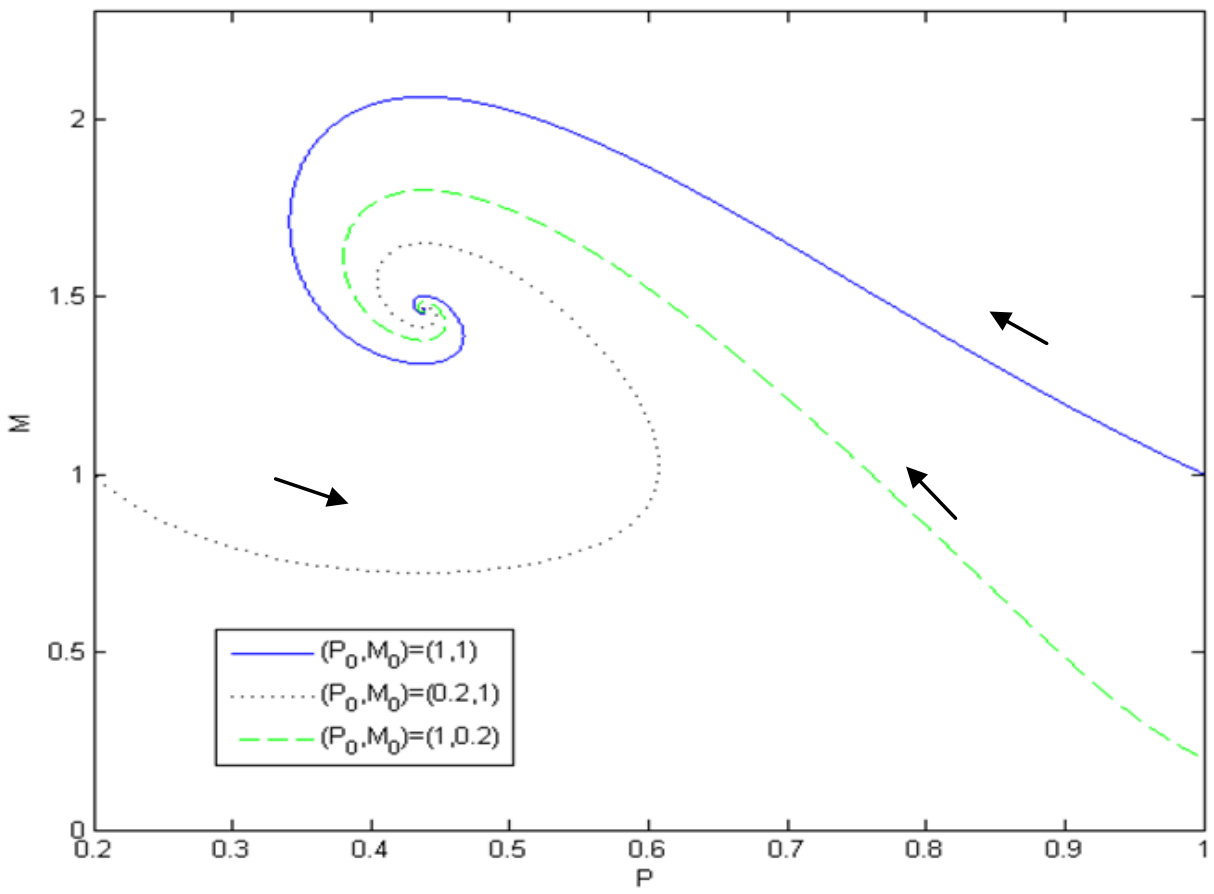

(b)

Fig. 4 Simulation results of mealybug and predator populations of the predator-prey model for $K=1, a=1.3, b=$ $0.5, d=1.6$ (4a) $c=3.2$ (4b) $c=0.7$. 


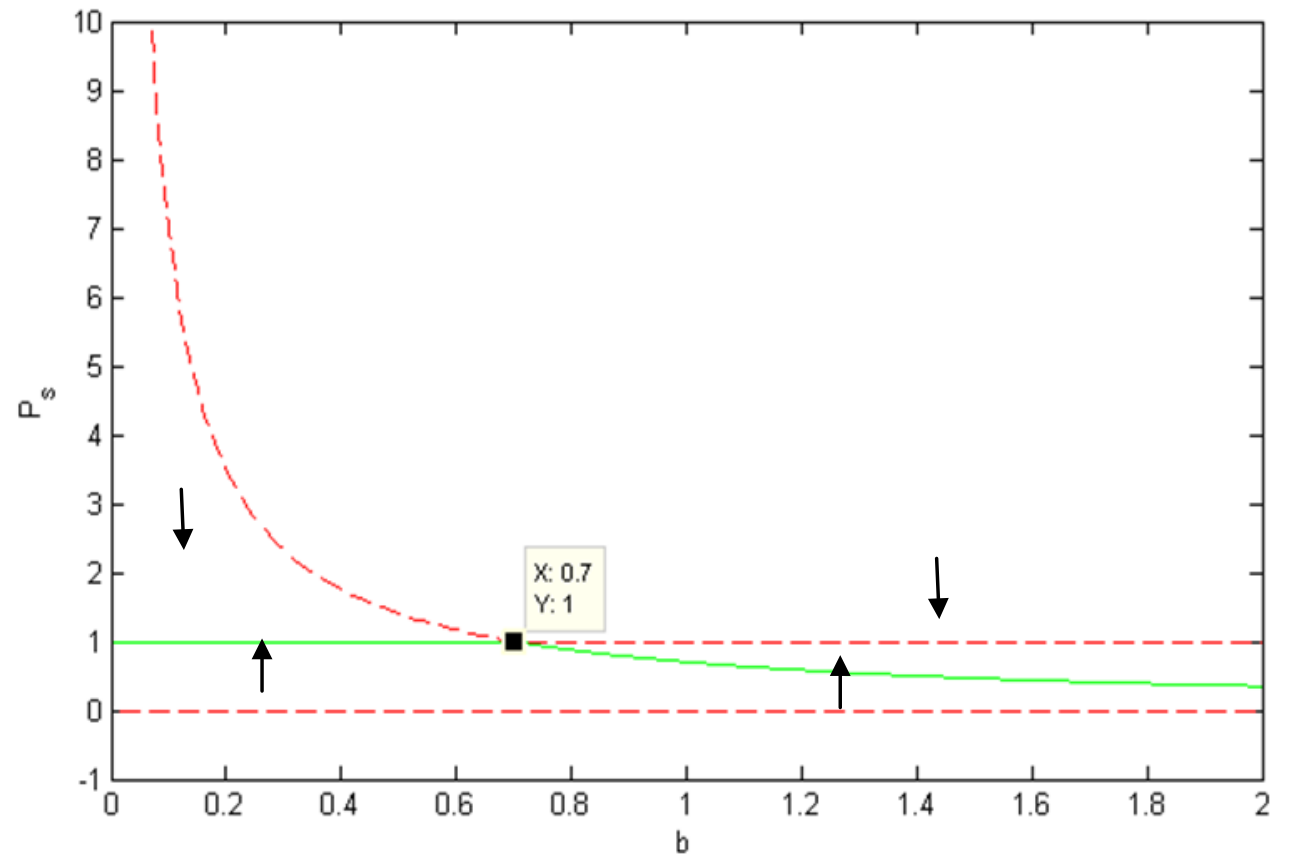

(a)

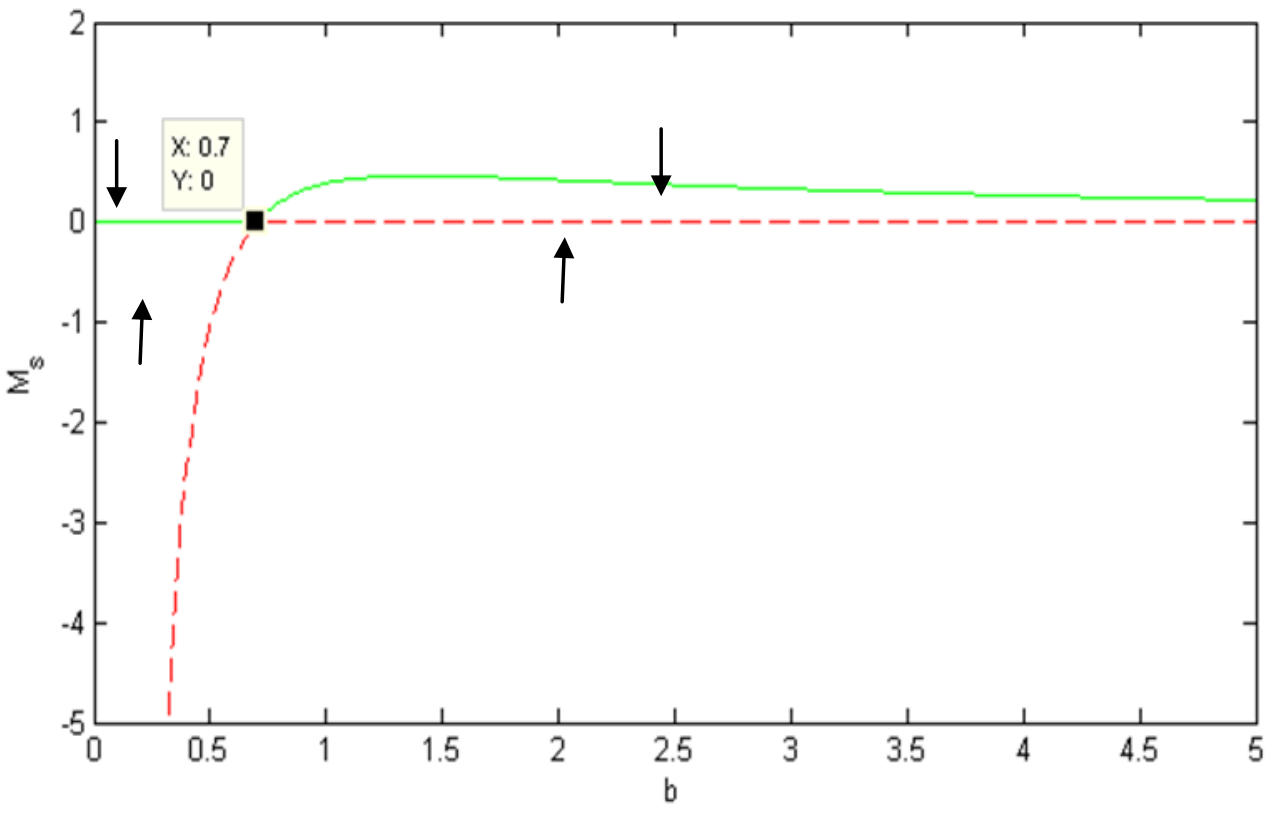

(b)

Fig. 5 Bifurcation diagrams of the predator-prey model for $K=1, a=1.3, c=0.7$ (5a) mealybug population (5b) predator population. 


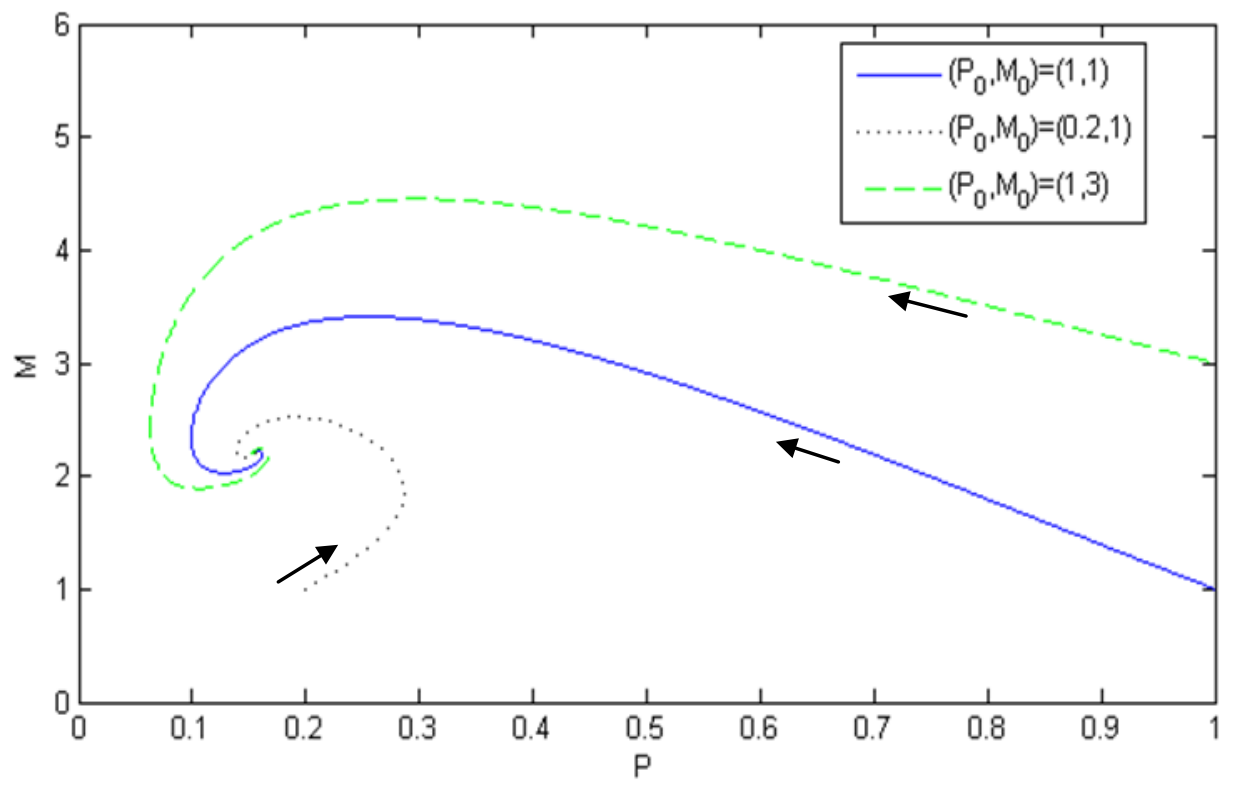

(a)

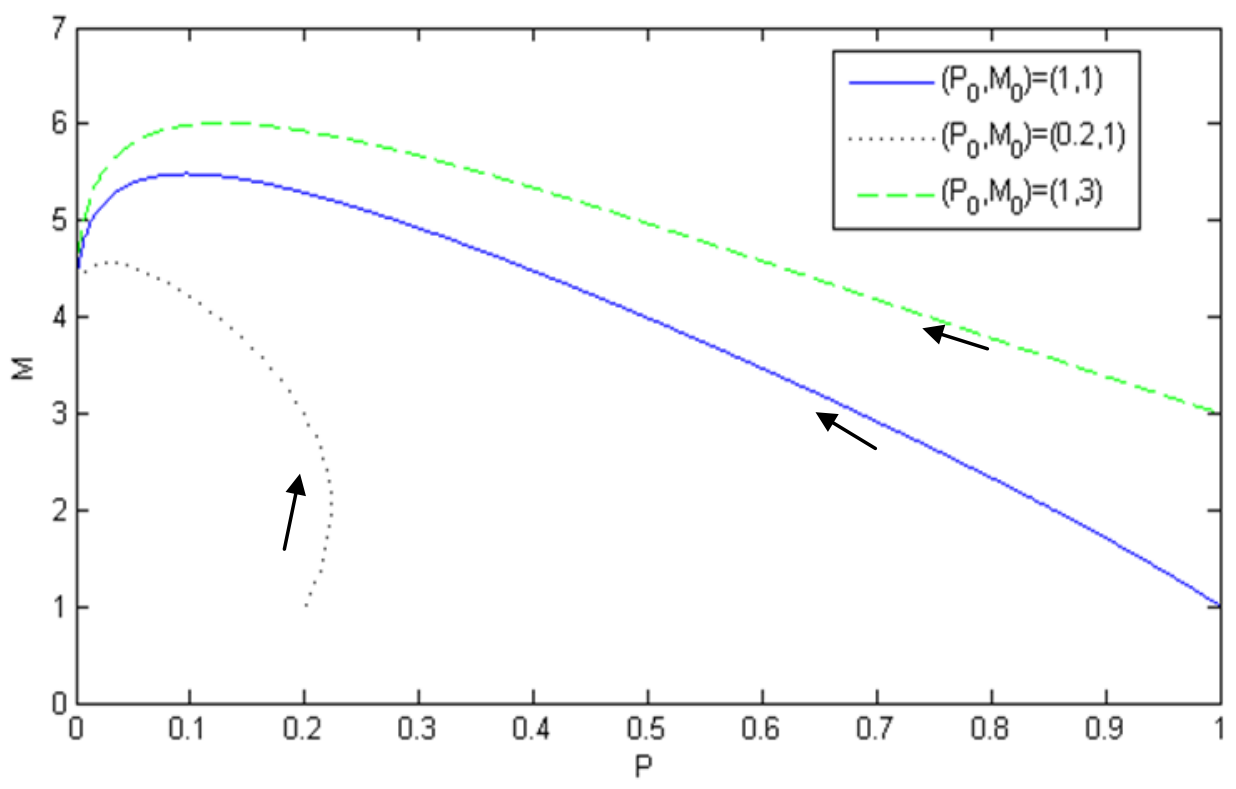

(b)

Fig. 6 Simulation results of mealybug population of modified predator-prey model for $K=1, a=1.3, b=0.5, c=$ $0.7, d=1.6$ (6a) $g=1$ (6b) $g=3$. 


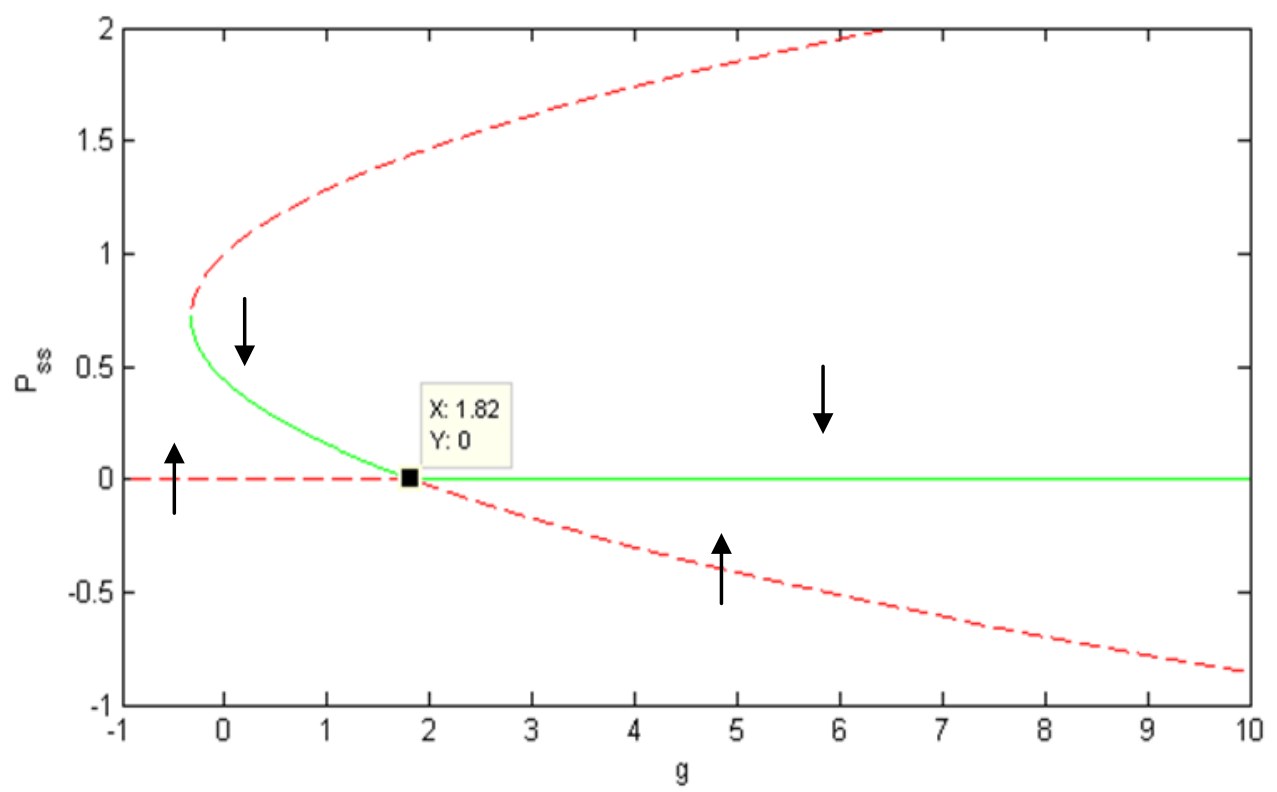

(a)

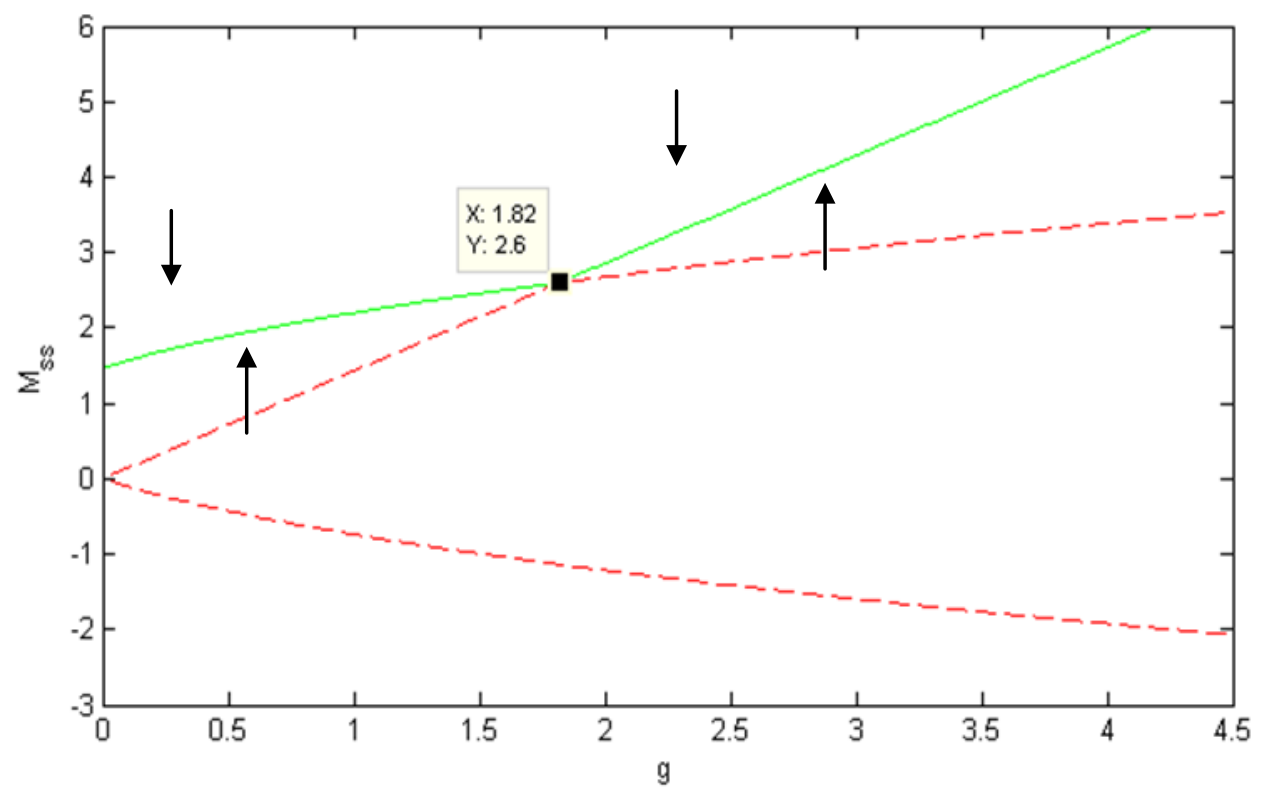

(b)

Fig. 7 Bifurcation diagrams of modified predator-prey model (7a) mealybug population (7b) predator population.

that population size of mealybug is dropped by increasing $g$ and it becomes zero after $g=a c / b$. Behaviour of predator population is divided into two cases, see Figure (7b). The first one occurs when $g<a c / b$; solutions grow logistically while $g$ is enlarged. The second type is for $g>a c / b$; solutions linearly increase corresponding to higher rate $g$.
Comparisons of the results of two models are shown in Figures (8) and (9) where figures on the left and the right hand sides represent the simulation results of biological control models of continuous and periodic predator-adding, respectively. Two values of $g$ are studied: $g=1 \quad(g<a c / b)$ and $g=3$ $(g>a c / b)$. 


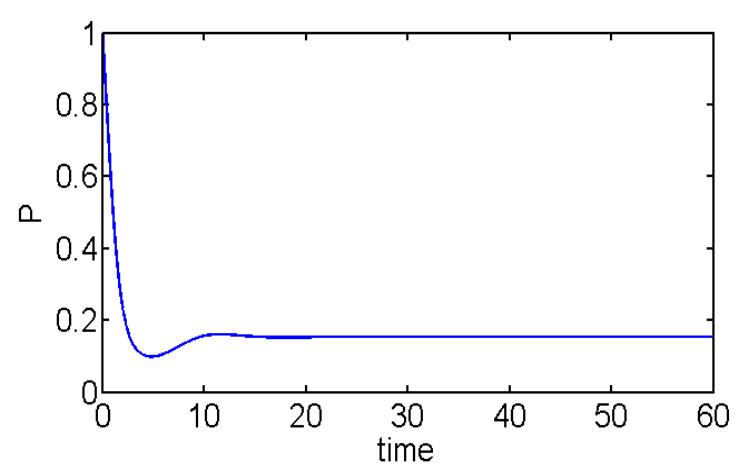

(a)

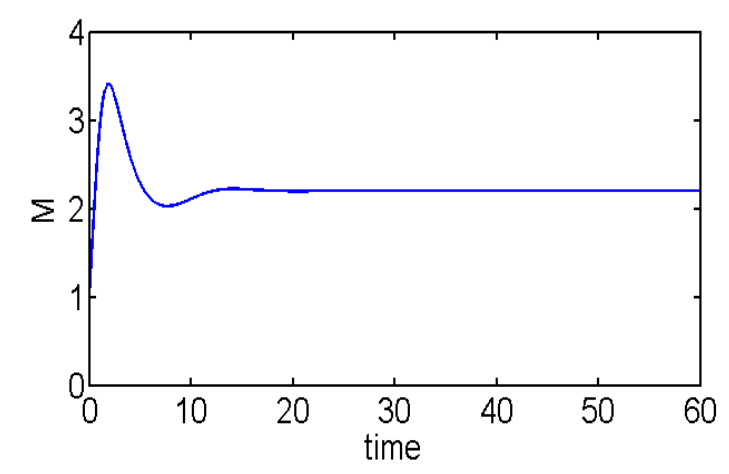

(b)

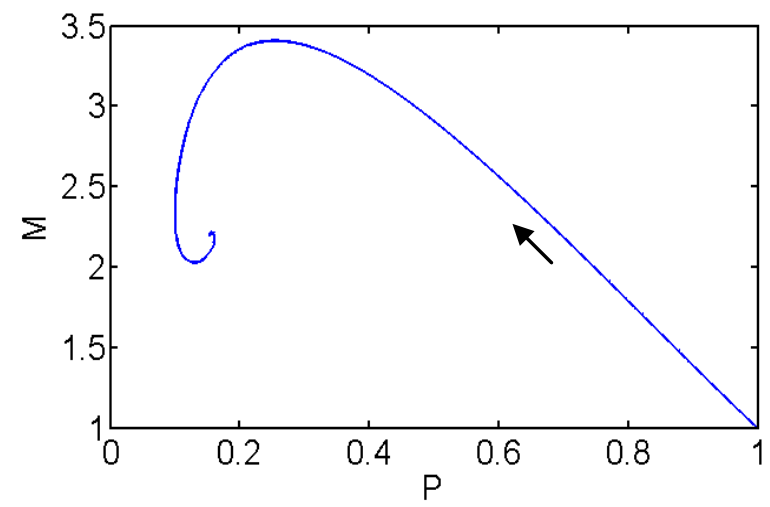

(c)

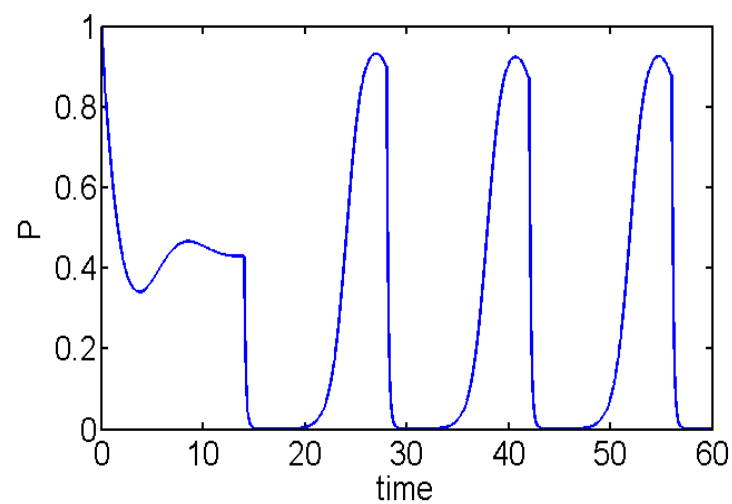

(d)

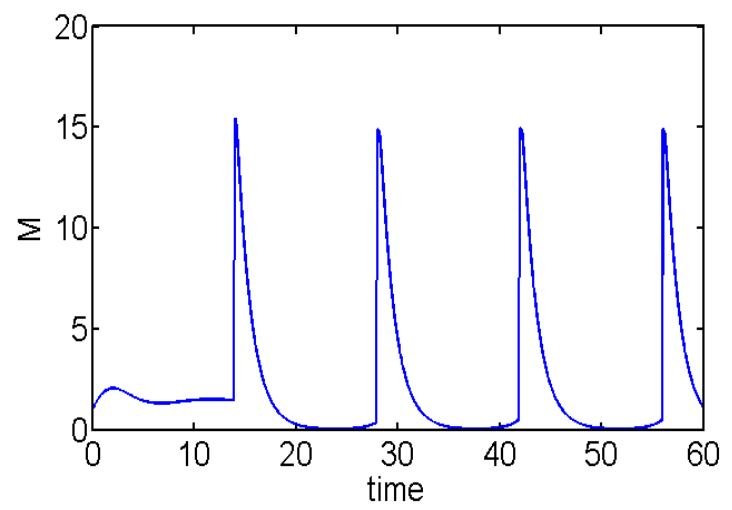

(e)

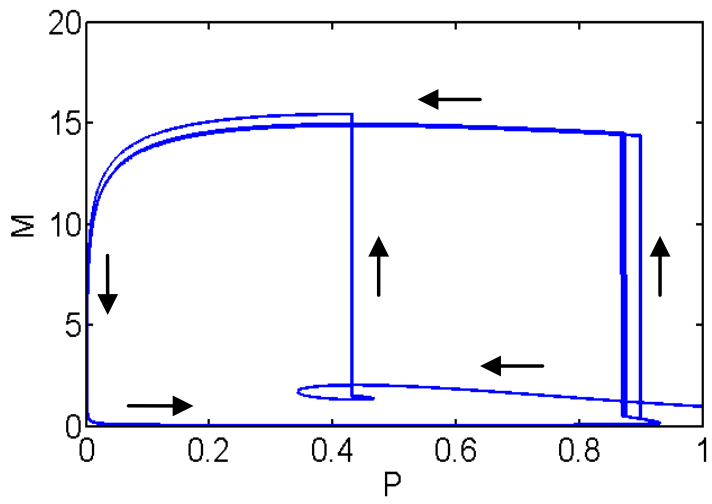

(f)

Fig. 8 Comparison of the results between models of equations (5-6) (left hand side) and equations (16-18) (right hand side) for $g=1, K=1, a=1.3, b=0.5, c=0.7, d=1.6,\left(P_{0}, M_{0}\right)=(1,1), \Delta t=14$. 


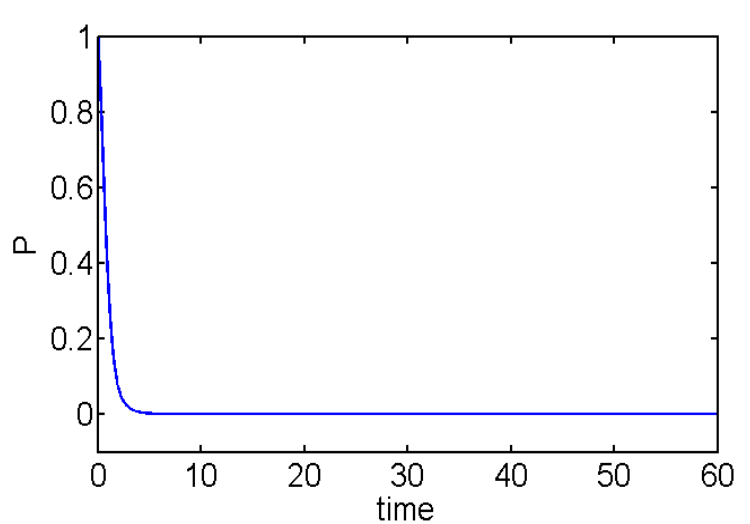

(a)

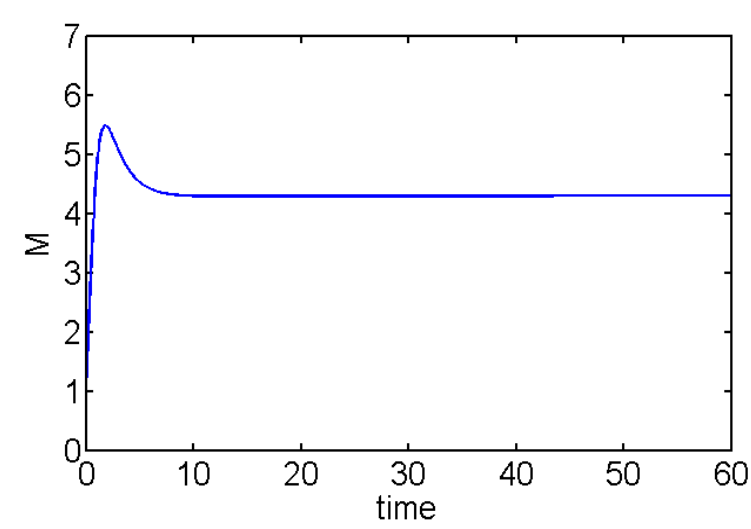

(b)

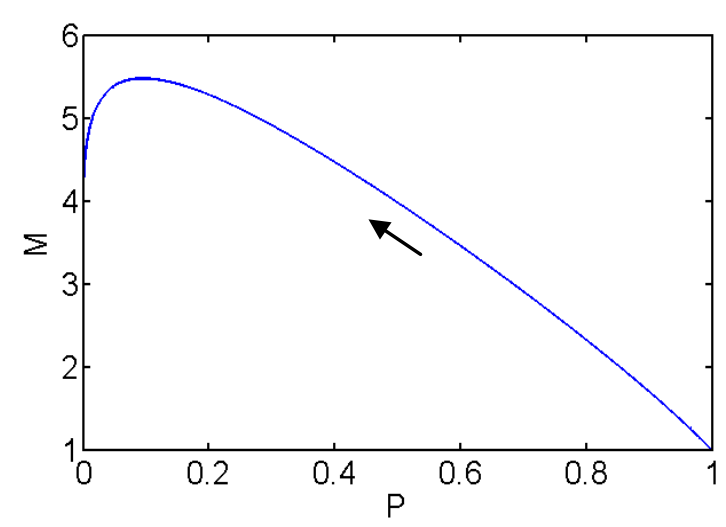

(c)

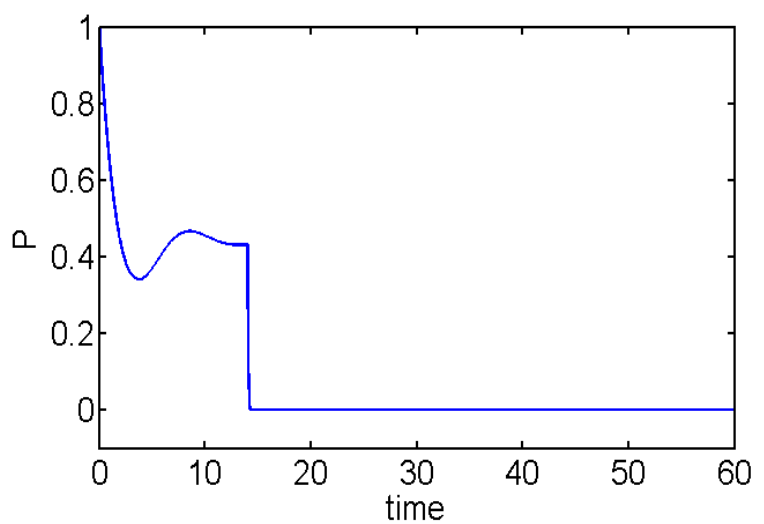

(d)

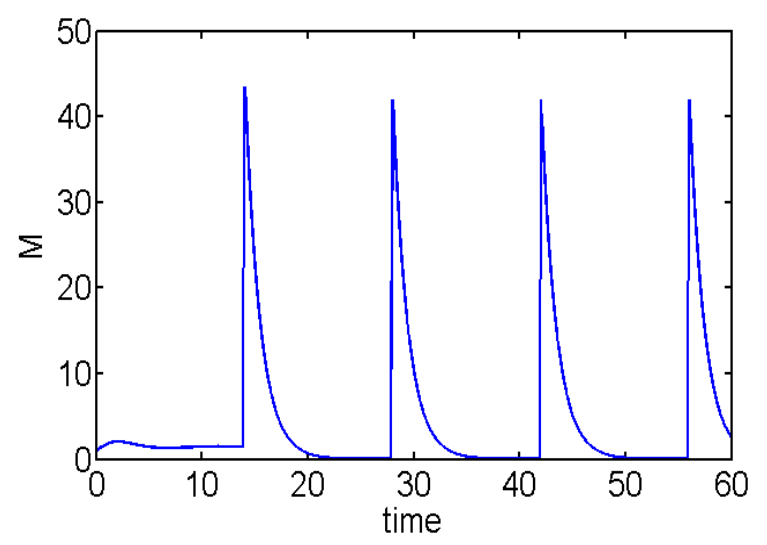

(e)

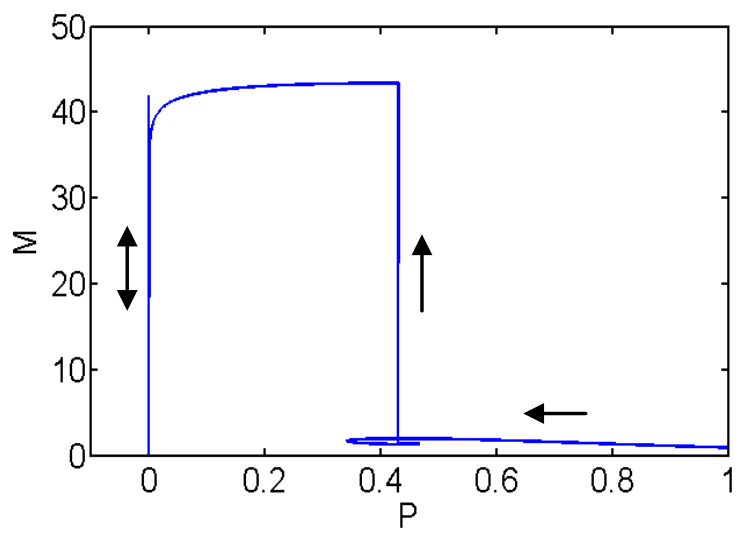

(f)

Fig. 9 Comparison of the results between models of equations (5-6) (left hand side) and equations (16-18) (right hand side) for $g=3, K=1, a=1.3, b=0.5, c=0.7, d=1.6,\left(P_{0}, M_{0}\right)=(1,1), \Delta t=14$. 
From Figures (8f) and (9f) satisfying impulse effect model, we obtain the periodic solutions with coexisting-species for $g=1$ and with mono-species for $g=3$.

\section{Discussion}

From the simulation results shown in Figures 4, we verify that our solutions will converge to mono-population $(P, M)=(K, 0)$ if $d K<c$. Otherwise, the long term steady-state solution is $(P, M)=\left(\frac{c}{d}, \frac{a}{b}\left(1-\frac{c}{d K}\right)\right)$. That is, for a non-control situation, some mealybugs survive finally. Moreover, from Figures (5a) and (5b), we can see that the bifurcation occurs at $b=d=c / K$.

After introducing its natural enemy, the size of the population of mealybugs is decreasing as desired. With the same conditions, the mealybug's level reduces from 0.45 (as a proportion) in Figure (4b) to 0.18 in Figure (6a). From Figures (6a) and (6b), we can see that if more predators are added, more mealybugs are eliminated. Furthermore, bifurcation diagram in Figure (7a) reveals that if added predator rate is more than $a c / b$, the mealybugs are driven to extinction.

Furthermore, our experiment provides the same trend for two models of biological control (continuous or impulse effect) that is if we add large enough amount of predator, mealybugs can be eliminated, see Figures (8) and (9).

In future work, the multistage physiological structures of the predator and prey will be taken into account before applying such model to the real experimental data.

\section{Conclusion}

This work presents mathematical models for a mealybug population with biological control. The stability of the system has been analyzed by the eigenvalue-eigenvector method. Some examples of relationship between the predator and its prey are given in terms of phase planes. The simulation results obtained from different parameters are compared. Finally, the bifurcation diagrams have been proposed in order to describe the overall behaviour of our models. In particular we discover thresholds of the predator release-rate which can eliminate mealybugs ultimately.

\section{Acknowledgement}

This work was supported by the Development and Promotion of Science and Technology Talents Project (DPST), Thailand, The Thailand Research Fund and the Centre of Excellence in Mathematics, Thailand.

\section{References}

[1] Bartlett, B.R., 1978. Pseudococcidae. In: Introduced Parasites and Predators of Arthropod Pests and Weeds: a World Review (Ed. Clausen CP), pp. 137-170. Agriculture Handbook no. 480. USDA, Washington (US).

[2] Baskaran, R. K. Murali, Mahendhiran, G., Suresh, K., 2007. Field evaluation of Scymnus coccivora Ayyar for the management of guava mealybug, Maconellicoccus hirsutus Green. Journal of Entomological Research (New Delhi). 31(2), 137-140.

[3] Bokonon-ganta, A.H., Neuenschwander, P., 1995. Impact of the biological control agent Gyranusoidea tebygi Noyes (Hymenoptera: Encyrtidae) on the mango mealybug, Rastrococcus invadens Williams (Homoptera: Pseudococidae), in Benin. Biocontrol Science and Technology. 5, 95-107.

[4] Department of agriculture, Thailand, 2008. Technology in cassava production to solve mealybug problems, http://agrimedia.agritech.doae.go.th/book/book-rice/RB\% 20043.pdf. Accessed August 2014.

[5] Herren, H.R., Neuenschwander, P., 1991. Biological control of cassava pests in Africa. Annu. Rev. Entomol. 36, 257-283.

[6] Institute of Science in Society, UK, 2010. Mealy Bug Plagues Bt Cotton in India and Pakistan, http://www.i-sis.org.uk/mealybugPlaguesBtCotton.php. Accessed December 2015.

[7] Kairo, M.T.K., Pollard, G.V., Peterkin, D.D., Lopez, V.F., 2000. Biological control of the hibiscus mealybug, Maconellicoccus hirsutus Green (Hemiptera: Pseudococcidae) in the Caribbean. Integrated Pest Management Reviews, 5, 241-254.

[8] Mani, M., Krishnamoorthy, A., 2008. Biological suppression of the mealybugs Planococcus citri (Risso), 
Ferrisia virgata (Cockerell) and Nipaecoccus viridis (Newstead) on pummelo with Cryptolaemus montrouzieri Mulsant in India. Journal of Biological Control. 22, 169-172.

[9] Moffitt, L. J. 1999. Economic Risk to United States Agriculture of Pink Hibiscus Mealybug Invasion. A report to the United States Department of Agriculture, Animal and Plant Health Inspection Service. USDA. 15 pp.

[10] Moore, D., 2004. Biological control of Rastrococcus invadens. Biocontrol News and Information. 25(1), $17 \mathrm{~N}-27 \mathrm{~N}$.

[11] Nagrare, V.S., Kranthi, S., Biradar, V.K., Zade, N.N.,
Sangode, V., Kakde, G., Shukla, R.M., Shivare, D., Khadi, B.M., Kranthi, K.R., 2009. Widespread infestation of the exotic mealybug species, Phenacoccus solenopsis (Tinsley) (Hemiptera: Pseudococcidae), on cotton in India. Bulletin of Entomological Research. 99, 537-541.

[12] Royal Horticultural Society, UK, 2015. Mealybug, https://www.rhs.org.uk/advice/profile?PID=201. Accessed December 2015.

[13] Ujjan, A.A., Shahzad, S., 2007. Pathogenicity of Metarhizium anisopliae var acridum strains on pink hibiscus mealy bug (Maconellicoccus hirsutus) affecting cotton crop. Pakistan Journal of Botany. 39(3), 967-973. 